\title{
Empirical modelling of river water temperature in water scarce European basins
}

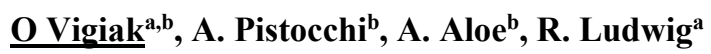 \\ ${ }^{a}$ Ludwig-Maximilian-Universitaet of Muenchen, Dept. of Geography, Luisenst 37, Munich, Germany \\ ${ }^{b}$ European Commission, Joint Research Centre (JRC), Directorate D - Sustainable Resources, Italy \\ Email: olga.vigiak@gmail.com
}

\begin{abstract}
GLOBAQUA is a European Union (EU)-funded project aiming to identify the prevalence of, and interaction between, stressors under water scarcity in order to improve water management practices and policies. River water temperature (RWT) plays a pivotal role in aquatic freshwater ecosystems, impacting the distribution of aquatic species and water quality. In this study, we aimed at assessing RWT in three data-poor, water scarce basin of the European Mediterranean region to enable projections of RWT as one of the multiple stressors that aquatic habitats face currently and likely more in the future. Given that water thermal inertia regulates RWT response to Ta, stream discharge $(\mathrm{Q})$ should be considered in predicting RWT in water scarce basins. To be pragmatic, we opted for applying a published empirical regression of RWT as a function of Ta and Q for application in three European basins, namely the Adige (Italy, 28 stations), the Ebro (Spain, 39 stations), and the Sava (Western Balkans, 10 stations). Time series comprised data observed from 1967 to 2014; observed RWT ranged from -5 to $34{ }^{\circ} \mathrm{C}$, Ta ranged from -50 to $39^{\circ} \mathrm{C}$ and stream discharge ranged from 0 to $5000 \mathrm{~m}^{3} / \mathrm{s}$. For each basin, the regression coefficients were estimated with Bayesian inference using a calibration dataset that comprised about $75 \%$ of basin stations. Initial collinearity analysis showed that correlation between regression coefficients reduced identifiability of all empirical parameters, thence the asymptotic minimum RWT was set at zero while the asymptotic maximum was set according to the distribution of the highest $4 \%$ of recorded RWT. MCMC runs converged to acceptable solutions in all basins. The root mean square error (RMSE) in the calibration and in the validation datasets varied from 2 to $3.15^{\circ} \mathrm{C}$, which was deemed acceptable for application at basin scale. However, while statistic results were acceptable, the projected impact of stream discharge on RWT resulted to be either negligible (in the Sava basin) or unrealistic, e.g. in the Adige basin. Furthermore, the empirical equation seemed conceptually flaw at low temperatures, where low discharge would increase rather than decrease RWT. Repeating the analysis after dropping the stream discharge variable allowed reaching the same estimation errors, i.e. neglecting the hypothesized discharge impact did not degrade the empirical RWT estimation. In view of data limitations, the logistic regression of RWT as a function of Ta was considered sufficient to assess RWT changes in foreseeable future in the three studied basins. We further conclude that despite statistical convergence and acceptable goodness of fit, the hypothesized empirical relationship of RWT and Q should be revised. Alternatively, in data richer environments, stream discharge could be used in regionalization schemes to extend regression parameters in between observation stations.
\end{abstract}

Keywords: $\quad$ River water temperature, empirical regression, water quality, Globaqua project 
Vigiak et al., Empirical modelling of river water temperature in water scarce Mediterranean basins

\section{INTRODUCTION}

River water temperature (RWT) plays a pivotal role in aquatic freshwater ecosystems, and largely influences invertebrate and fish habitats, the distribution of aquatic species, as well as stream water quality (Cassie, 2006; Webb et al., 2008). RWT is influenced by several environmental factors, namely atmospheric conditions, topography, stream discharge, and streambed characteristics (Cassie, 2006). These factors determine the heating exchanges that occur in the stream continuum. In addition, human activities can act on river temperature by withdrawing water, altering riparian vegetation and stream shading, and/or releasing warm or cold water from industrial plants and dams.

Modelling of RWT can be achieved through empirical regressions, stochastic, and deterministic models (Cassie, 2006). The simplest model consists of establishing a linear regression between RWT and air temperature (Ta). The regression can be fitted at weekly, monthly or annual time scales. Fitting at daily scale may be difficult due to autocorrelation in the time series (van Vliet et al., 2011; Soto, 2016). As the time step of the regression increases, the slope of the regression line of RWT on Ta usually decreases, but the change may depend on the stream type (Cassie, 2006). A linear relationship is usually satisfactory in the $5-25^{\circ} \mathrm{C}$ range, however at lower or higher Ta, the relationship becomes non-linear, as water thermal inertia starts to play an important role, with RWT usually higher than Ta in cold periods, and RWT cooler than Ta during hot days. To capture this non-linearities, Mohseni et al. (1998) proposed a four parameter logistic regression between daily RWT and Ta that constrained RWT range between an asymptotic minimum and an asymptotic maximum, and several studies confirmed that the logistic regression generally outperforms the linear equation (e.g. Mohseni et al., 2002; Morrill et al., 2005). Stochastic models divide RWT and Ta time-series in a long term component, related to the annual cycle, and a short term component. Finally, deterministic models quantify the energy flux in a river reach and relate it to RWT. The physical basis of deterministic models is appealing, especially for application in reaches where RWT data is not available. However, they require solving daily heat balance at each reach, and need data for calibration and to set boundary conditions. The root mean square error (RMSE) of empirical and stochastic models fitted at a specific station is usually $<2{ }^{\circ} \mathrm{C}$; deterministic and hybrid models can reduce RMSE where thermal regime is influenced by upstream lakes or thermal pollution points. For application over large areas, regression and stochastic models could in theory be easily applied as they require only Ta data (Cassie, 2006). However, multiple sites are usually fitted independently, i.e. a specific fit is valid for a specific station (Cassie, 2006). Nevertheless, spatial correlation exists in reaches of a given region (e.g. Letcher et al., 2016) and site-specific regressions have been applied over larger areas (e.g. van Vliet et al., 2013; Punzet et al., 2012).

As Ta is a very good predictor for RWT, it can be expected that in the future RWT will increase with increases in Ta. Correlated trends have indeed already been observed in some European rivers (e.g. Soto, 2016). Several studies assessed the potential impact of climate change on RWT. Morrill et al. (2005) used Mohseni et al. (1998) approach to forecast RWT in 43 sites of the USA and found that on average an increase of RWT of 0.6$0.8^{\circ} \mathrm{C}$ can be expected for a $1^{\circ} \mathrm{C}$ change in Ta, although some variance was reported between sites. Punzet et al. (2012) applied a similar approach to climate regions of the world to forecast potential changes of stream temperature at global scale. These studies neglected potential impacts of reach discharges on RWT. Due to water thermal capacity, stream discharge (Q) is an important factor in regulating RWT response to Ta (e.g. Soto, 2016), although its impact may depend on stream conditions. Sohrabi et al. (2017) found that discharge response was important in snow melt conditions or in regulated rivers. To account for correlated changes in Q and Ta, Van Vliet et al. (2011) modified Mohseni et al. (1998) approach by adding a factor that is inversely proportional to Q. Inclusion of $\mathrm{Q}$ as independent variable improved RWT estimation in $87 \%$ of 157 sites of their global river dataset. Their sensitivity analysis showed that decreases of Q by 20 and $40 \%$ could further increase RWT by 0.3 and $0.8^{\circ} \mathrm{C}$. In contrast, Pyka et al. (2016) found that discharge impact predicted with van Vliet et al. (2011) method was negligible on climate change projections for the Meuse River.

GLOBAQUA is a European Union (EU)-funded project aiming to identify the prevalence of, and interaction between, stressors under water scarcity in

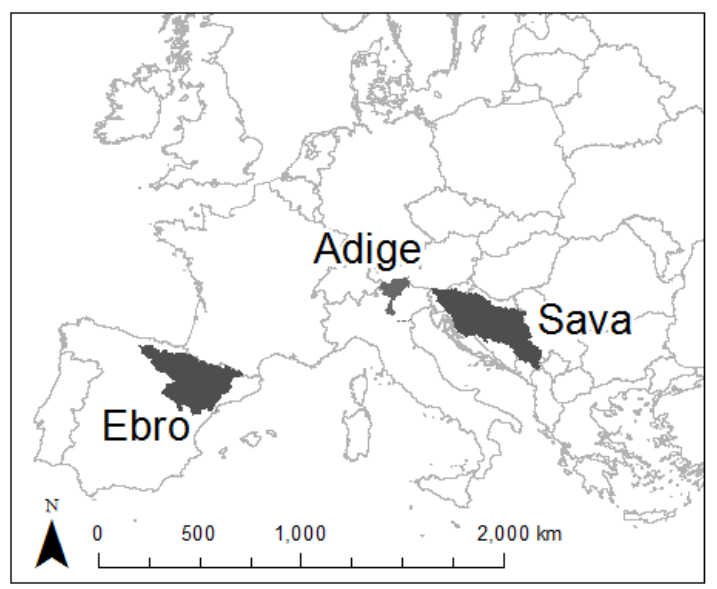

Figure 1. Location and extent of the three Globaqua basins where the study was conducted. 
Vigiak et al., Empirical modelling of river water temperature in water scarce Mediterranean basins

order to improve water management practices and policies. In order to assess changes in RWT in aquatic environments subject to multiple stressors and under water scarcity conditions, relationships between environmental drivers and RWT must be established. The aim of this work was to develop an empirical approach to forecast RWT, as one stressor among others affecting the aquatic status of the streams.

\section{THE GLOBAQUA BASINS}

The analysis was conducted in three European basins (Figure 1). The Adige River is $410 \mathrm{~km}$ long and its basin is about $12000 \mathrm{~km}^{2}$. The climate is characterized by dry winters, snowmelt in the spring, and humid summer and falls. There are 30 major reservoirs to supply hydropower plants. Foreseen climate change impacts include anticipation of snow melting, increase of temperature and reduction of water resources during summer, at the peak of agricultural and recreational use demands.

The Ebro River Table 1. Characteristics of basin datasets. For each variable the mean value of the dataset develops along $928 \mathrm{~km}$ and drains a basin of $85,550 \mathrm{~km}^{2}$ in Spain. The basin hosts more than 2.7 million

inhabitants. The Ebro is largely regulated by dams and channels.

Forests cover $24 \%$ of the basin, while shrublands and grasslands cover $\quad 23 \%$. is reported. Values in brackets are the $2.5^{\text {th }}$ and $97.5^{\text {th }}$ percentile of the distributions.

\begin{tabular}{|c|c|c|c|c|}
\hline & & Adige & Ebro & Sava \\
\hline & Period & 1993-2014 & $1980-2014$ & $1967-2013$ \\
\hline \multirow{5}{*}{ 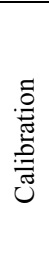 } & \# stations & 24 & 30 & 7 \\
\hline & \# entries & 1048 & 8667 & 1117 \\
\hline & RWT ${ }^{\circ} \mathrm{C}$ & $8.6(1.0-16.4)$ & $12.9(4.1-18.3)$ & $13.3(2.3-25.6)$ \\
\hline & $\mathrm{Ta}{ }^{\circ} \mathrm{C}$ & $13.0(1-28)$ & $16.0(2-23)$ & $12.8(-4 ; 30.4)$ \\
\hline & $\mathrm{Q} \mathrm{m} 3 / \mathrm{s}$ & $54.8(0.8-242.4)$ & $30.9(0.12-31.0)$ & $504(0.2-2559.1)$ \\
\hline \multirow{5}{*}{ 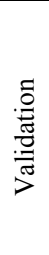 } & \# stations & 4 & 9 & 3 \\
\hline & \# entries & 216 & 1462 & 895 \\
\hline & $\mathrm{RWT}^{\circ} \mathrm{C}$ & $8.9(1.5-18.5)$ & $13.5(4.1-18.6)$ & $13.1(2.5-26.0)$ \\
\hline & $\mathrm{Ta}^{\circ} \mathrm{C}$ & $13.9(1-28.6)$ & $16.1(1.8-23.3)$ & $13.4(-2.8 ; 30.5)$ \\
\hline & $\mathrm{Q} \mathrm{m} 3 / \mathrm{s}$ & $129(0.08-331.3)$ & $7.8(0.03-8.7)$ & $801(0 ; 3348.5)$ \\
\hline
\end{tabular}

Urban, industrial areas, and water bodies cover about 2\%. Abstraction of ground and surface water, together with pollution from agricultural and industrial activities highly impact the river water quality.

The Sava River $(945 \mathrm{~km})$ is the largest tributary to the Danube River in the Western Balkans. Its basin extends over 97,000 $\mathrm{km}^{2}$ across Slovenia, Croatia, Bosnia and Herzegovina, and Serbia. Mean annual precipitation range between $3000 \mathrm{~mm}$ per year in the headwater to around $660 \mathrm{~mm}$ at the confluence with the Danube. Mean annual temperature ranges from $6{ }^{\circ} \mathrm{C}$ in the headwaters to $13^{\circ} \mathrm{C}$ at its mouth. The population in the Sava basin is about 8.2 million. The basin is covered by forest and semi-natural areas (55\%) and agricultural surfaces $(42 \%)$.

Available time-series of RWT, Ta and Q (Table 1) were discontinuous, i.e. RWT, Ta, and Q were reported only for sampling days, usually of monthly frequency, and thus autocorrelation in the time-series could not be assessed.

\section{RWT REGRESSION APPROACH}

In consideration of limited data and resources, van Vliet et al. (2011) logistic regression was selected as suitable to provide a first assessment of RWT changes under water scarcity conditions:

$R W T=\mu+\frac{\alpha-\mu}{(1+\exp \gamma(\beta-T a))}+\frac{\eta}{Q}+\varepsilon$

where RWT $=$ River Water Temperature $\left({ }^{\circ} \mathrm{C}\right) ; \mathrm{Ta}=$ air Temperature $\left({ }^{\circ} \mathrm{C}\right) ; \mathrm{Q}=$ streamflow $\left(\mathrm{m}^{3} / \mathrm{s}\right)$. The first two right terms correspond to Mohseni et al. (1998) approach with $\mu=$ minimum temperature; $\alpha=$ maximum temperature; $\beta=$ air temperature at the inflection point; and $\gamma=$ measure of the slope at the inflection point. Van Vliet et al. (2011) added the parameter $\eta\left({ }^{\circ} \mathrm{Cs} / \mathrm{m}^{3}\right)$ to account for discharge, while $\varepsilon$ is the error term $\left({ }^{\circ} \mathrm{C}\right)$.

Equation (1) can be applied at daily timescale. Ideally, it should be fitted independently at each station. However, given that RWT projections were needed across the basins, we elected to fit it at basin scale, 
assuming that Q could be considered as the major environmental proxy explaining the variability of RWT/Ta relationship across a basin. The assumption was based on evidence that RWT-Ta relationship can be dependent on water residence time and Q (Soto, 2016). Monitoring stations were split randomly into a larger calibration dataset of about $80 \%$ of stations and a smaller validation dataset (Table 1).

Parameters were estimated with a Bayesian inference framework using the Flexible Model Environment package in R (FME; Soetaert and Petzold, 2010). The FME method consists of four steps: 1) preliminary sensitivity analysis, from which parameters to be estimated are selected; 2) analysis of parameter identifiability, which considers parameter collinearities to identify parameter sets that can be concurrently estimated; 3) optimization of initial model simulations; and 4) run Markov-Chain Monte Carlo (MCMC) simulations against data.

Initial model parameter distributions were set uniform with ranges that depended on the observed ranges in each basin. Collinearity showed that $\mu$ was highly correlated with both $\alpha$ and $\gamma$. To reduce collinearity, $\mu$ was set to $0{ }^{\circ} \mathrm{C}$ (e.g. Segura et al., 2015). This is justified as at cold temperatures RWT becomes decoupled to Ta (Letcher et al., 2016). The parameter $\alpha$ that defines maximum RWT is important for climate change projections as a likely maximum RWT may not have been observed. Punzet et al. (2012) reported that maximum RWT in a global dataset of more than 100,000 data entries was $34.8{ }^{\circ} \mathrm{C}$. Mohseni et al. (2002) defined RWT upper bounds based on the mean and standard deviation of the maximum temperatures in the time-series. We set $\alpha$ with Mohseni et al. (2002) method, using the 4\% highest RWT values of basin datasets, and the enveloping standard deviate $\mathrm{KE}=4.88$ (Mohseni et al., 2002). To account for the large variability of $\mathrm{Q}$ across basin stations (Table 1) streamflow was log-transformed. Thus, equation (1) became:

$R W T=\frac{\alpha}{\left(1+\exp ^{p_{2}\left(p_{1}-T a\right)}\right)}+\frac{p_{3}}{\log (Q+1)}+\varepsilon$

where $\mathrm{p}_{1}=\beta ; \mathrm{p}_{2}=\gamma$, and $\mathrm{p}_{3}=\eta$ of equation (1). The objective of optimization and MCMC runs was to minimize model residuals. MCMC runs were performed with the DRAM (Delayed Rejection Adaptive Metropolis) algorithm. MCMC number of runs was set at 10.000 with 2500 runs of warm-up. Convergence of MCMC parameters was checked visually to ensure validity of inference for $95 \%$ credible intervals of posterior parameter sets.

\section{RESULTS}

MCMC runs converged to well identified posterior distributions in all basins. As an example, Figure 2 shows posterior parameter distributions in the Adige basin

Table 2 reports the central values and interquartile ranges of posterior parameter distributions for the three basins together with some goodness-of-fit statistics. Considerable differences can be noted in the posterior distributions, particularly for the discharge fitting parameter $\eta$, which reflect the large variability in observed RWT and Q of the three basins.

Goodness-of-fit criteria confirmed good predictive ability of the method (Table 2), with high coefficient of determination (R2)
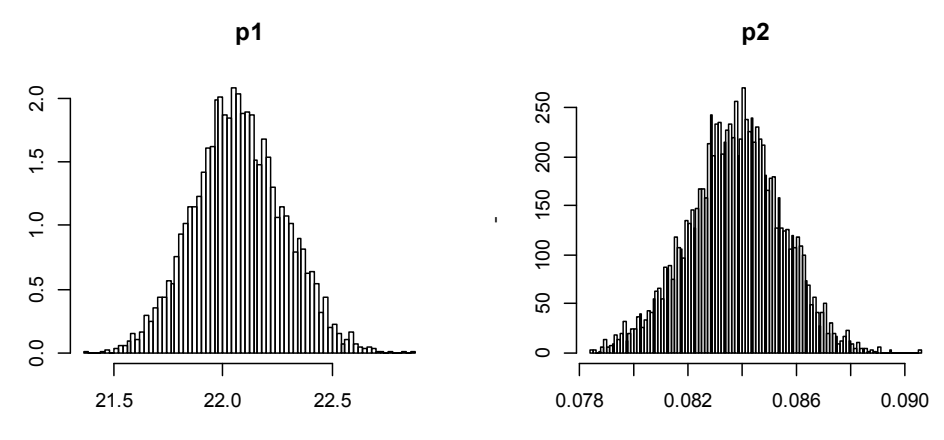

p3

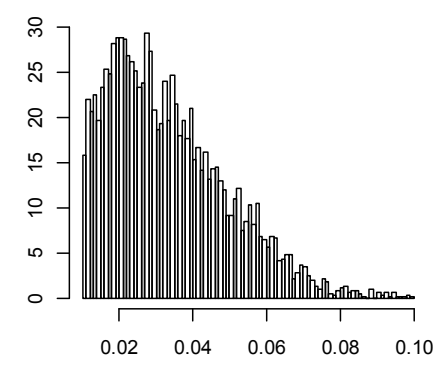

Figure 2. Bayesian posterior parameter distributions in the Adige Basin. 
Vigiak et al., Empirical modelling of river water temperature in water scarce Mediterranean basins

Table 2. Posterior parameters of eq. 1.bis for the Globaqua basins. Values in brackets are the $25^{\text {th }}$ and $75^{\text {th }}$ percentiles of the posterior distributions.

\begin{tabular}{|c|c|c|c|c|c|c|c|}
\hline & & \multicolumn{2}{|c|}{ Adige } & \multicolumn{2}{|c|}{ Ebro } & \multicolumn{2}{|c|}{ Sava } \\
\hline \multirow{5}{*}{ 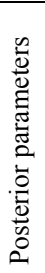 } & $\mu$ & \multicolumn{2}{|c|}{0} & \multicolumn{2}{|c|}{0} & \multicolumn{2}{|c|}{0} \\
\hline & $\alpha$ & \multicolumn{2}{|c|}{26} & \multicolumn{2}{|c|}{32} & \multicolumn{2}{|c|}{30} \\
\hline & $\beta$ & \multicolumn{2}{|c|}{$22.1(21.9-22.2)$} & \multicolumn{2}{|c|}{$21.5(21.0-21.1)$} & \multicolumn{2}{|c|}{$15.5(15.4-15.6)$} \\
\hline & $\gamma$ & \multicolumn{2}{|c|}{$0.084(0.083-0.085)$} & \multicolumn{2}{|c|}{$0.082(0.082-0.083)$} & \multicolumn{2}{|c|}{$0.099(0.097-0.100)$} \\
\hline & $\eta$ & \multicolumn{2}{|c|}{$0.030(0.023-0.043)$} & \multicolumn{2}{|c|}{$0.0028(0.0022-0.0033)$} & \multicolumn{2}{|c|}{$0.00027(0.00014-0.00045)$} \\
\hline \multirow{6}{*}{ 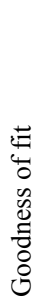 } & & Calibration & Validation & Calibration & Validation & Calibration & Validation \\
\hline & $\operatorname{RMSE}\left({ }^{\circ} \mathrm{C}\right)$ & 2.26 & 2.14 & 3.11 & 2.52 & 3.24 & 3.14 \\
\hline & PBIAS (\%) & 0.70 & 1.5 & 0.50 & -3.30 & 0.10 & 4.90 \\
\hline & RSR & 0.52 & 0.47 & 0.56 & 0.45 & 0.47 & 0.44 \\
\hline & NSE & 0.73 & 0.78 & 0.70 & 0.80 & 0.78 & 0.81 \\
\hline & R2 & 0.73 & 0.78 & 0.70 & 0.81 & 0.78 & 0.82 \\
\hline
\end{tabular}

and efficiency (NSE). RMSE were generally higher than what could be achieved in a station by station fit. However this can be expected in an application at the basin scale (e.g. Letcher et al., 2016) and considering that lag effect with previous days, which may be particularly important in large reaches (e.g. Soto, 2016; Sohrabi et al., 2017), could not be assessed due to discontinuities in the time-series. Further, the variance of observed RWT was high. The RSR mediates the error by the variability in the observed range; values lower than 0.70 (as in Table 2) indicate good predictions. Goodness-of-fit did not degrade in the validation datasets, thus from a statistical point of view the approach worked well.

\section{LIMITATIONS OF THE APPROACH}

Despite the good statistical results, both in terms of convergence and goodness of fit of the validation datasets, some important limitations in the approach should be highlighted. The discharge term allows for some flexibility in the RWT maxima at low discharges, however is its modelled impact realistic? There are no guidelines to constrain the parameter $\eta$. Sohrabi et al. (2017) found that discharge impact was important in

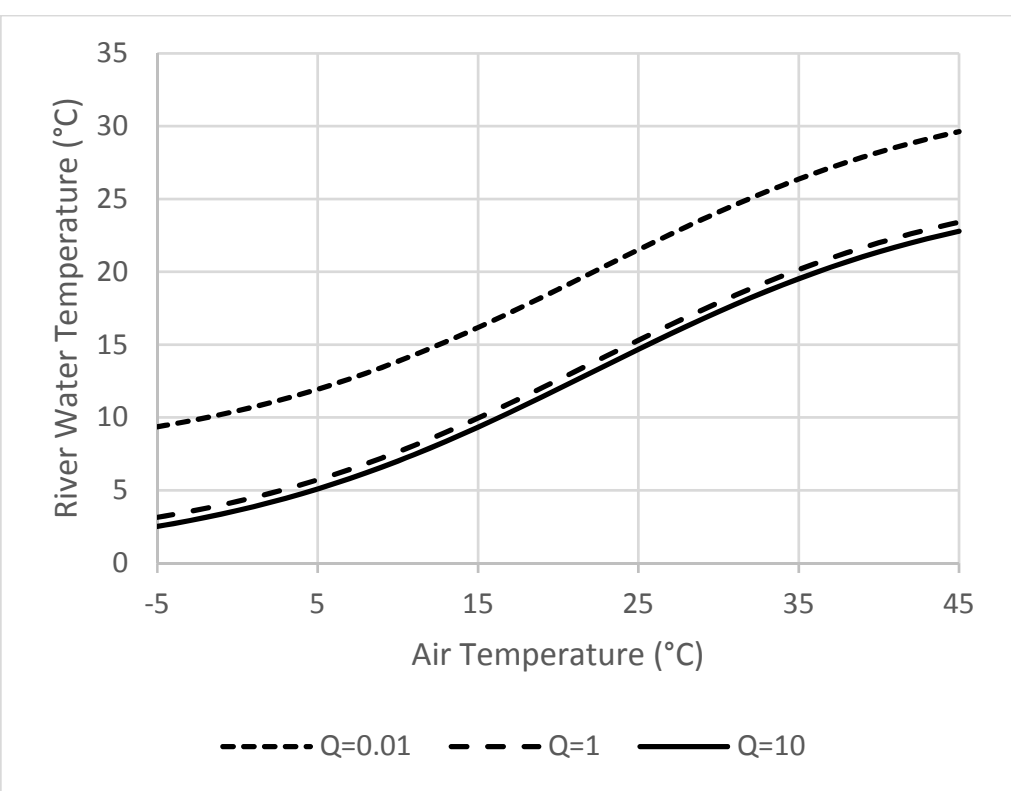

Figure 3. Simulated River Water Temperature $\left({ }^{\circ} \mathrm{C}\right)$ for Air temperature in the range of 0 to $45^{\circ} \mathrm{C}$ in the Adige basin at discharges $\mathrm{Q}$ of 0.01 , 0.1 , and $1 \mathrm{~m}^{3} / \mathrm{s}$ ). snow regimes and regulated rivers. Indeed, high $\eta$ in the Adige could reflect snow impact and regulation in the Ebro. In any case, it remains difficult to evaluate the physical meaning of the parameter $\eta$. Figure 3 show RWT simulation curves in a range of Ta from $0^{\circ} \mathrm{C}$ to $45^{\circ} \mathrm{C}$ at three low discharges (Q of $0.01 ; 0.1$ and $1 \mathrm{~m}^{3} / \mathrm{s}$ ) in the Adige Basin. A decrease of discharge $\mathrm{Q}$ from 0.1 to 0.01 $\mathrm{m}^{3} / \mathrm{s}$ results in an increase in RWT of $6^{\circ} \mathrm{C}$. A discharge of $0.01 \mathrm{~m}^{3} / \mathrm{s}$ is much lower than the observed (and measurable) range (Table 1), and unlike to occur in the basin, yet the increase in RWT seems unrealistic. Figure 3 indicates that eq. 1.bis should not be applied in the Adige at very low discharges. In the Ebro, the 
Vigiak et al., Empirical modelling of river water temperature in water scarce Mediterranean basins

modelled increase in RWT at Q of $0.01 \mathrm{~m}^{3} / \mathrm{s}$ is $0.6^{\circ} \mathrm{C}$ higher than for Q at $0.1 \mathrm{~m}^{3} / \mathrm{s}$, whereas in the Sava basin, the RWT difference would be of $0.1^{\circ} \mathrm{C}$. Conversely, at higher discharges, $\mathrm{Q}$ has no impact on RWT. Furthermore, there is another conceptual aspect that makes eq. (1) unsatisfactory: at low $\mathrm{Q}$ and low Ta we would expect that RWT would be colder rather than warmer, i.e. the relationship between Q and RWT should be

inverted.

Table 3. Posterior parameters of fitting Moheseni et al (1998) original equation in the Globaqua basins. Values in brackets are the $25^{\text {th }}$ and $75^{\text {th }}$ percentiles of the posterior distributions.

Given the unrealistic behavior of eq. 1.bis, the discharge term was dropped and the approach was reverted to the original Mohseni et al. (1998) equation, using only

\begin{tabular}{|c|c|c|c|c|c|c|c|}
\hline & & \multicolumn{2}{|c|}{ Adige } & \multicolumn{2}{|c|}{ Ebro } & \multicolumn{2}{|c|}{ Sava } \\
\hline \multirow{5}{*}{ 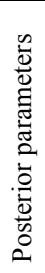 } & $\mu$ & \multicolumn{2}{|c|}{0} & \multicolumn{2}{|c|}{0} & \multicolumn{2}{|c|}{0} \\
\hline & $\alpha$ & \multicolumn{2}{|c|}{26} & \multicolumn{2}{|c|}{32} & \multicolumn{2}{|c|}{30} \\
\hline & $\beta$ & \multicolumn{2}{|c|}{$21.8(21.7-22 . .0)$} & \multicolumn{2}{|c|}{$21.2(21.17-21.26)$} & \multicolumn{2}{|c|}{$15.6(15.5-15.7)$} \\
\hline & $\gamma$ & \multicolumn{2}{|c|}{$0.084(0.083-0.086)$} & \multicolumn{2}{|c|}{$0.082(0.082-0.083)$} & \multicolumn{2}{|c|}{$0.100(0.098-0.101)$} \\
\hline & $\eta$ & \multicolumn{2}{|c|}{ NA } & \multicolumn{2}{|c|}{ NA } & \multicolumn{2}{|c|}{ NA } \\
\hline \multirow{6}{*}{ 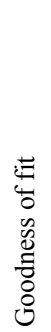 } & & Calibration & Validation & Calibration & Validation & Calibration & Validation \\
\hline & $\begin{array}{l}\text { RMSE } \\
\left({ }^{\circ} \mathrm{C}\right)\end{array}$ & 2.32 & 2.18 & 3.14 & 2.54 & 3.28 & 3.12 \\
\hline & PBIAS (\%) & 1.4 & 2.2 & 0.3 & -4.0 & 0.2 & 4.0 \\
\hline & RSR & 0.53 & 0.48 & 0.56 & 0.46 & 0.47 & 0.43 \\
\hline & NSE & 0.72 & 0.77 & 0.69 & 0.79 & 0.78 & 0.81 \\
\hline & R2 & 0.72 & 0.77 & 0.69 & 0.80 & 0.78 & 0.82 \\
\hline
\end{tabular}

Ta as RWT predictor. Table 3 reports parameters and goodness of fit for the three basins after dropping the parameter $\eta$ and variable $Q$. The fitted parameters did not change sensibly and the goodness of fit was not degraded, confirming that the discharge role on RWT was negligible in the datasets considered. This is in line with Pyka et al. (2016) findings that the discharge term in eq. (1) could be neglected, although in contrast with some other studies (e.g. Sohrabi et al., 2017 and works cited therein).

The role of discharge thus remains unclear. Segura et al. (2015) found that discharge could be useful to regionalize RWT regression parameters, however its inclusion could explain only $5 \%$ of the observed variance. Instead, baseflow index appeared to be more important, as important groundwater flow may reduce the RWT response to Ta. Soto (2016) found that discharge effect was important in determining the lag of reach response, with larger rivers being less sensitive to the air temperature of the day but more sensitive to the temperatures of previous days.

\section{CONCLUSIONS}

Application of van Vliet et al. (2011) logistic regression in three Mediterranean basins highlighted some unrealistic behaviors of the relationship, which suggests that the conceptualization of discharge impact on river water temperature should be revised. An alternative option, suitable in data-richer basins, could be to use discharge and baseflow index as environmental proxies to extrapolate Mohseni et al. (1998) parameters to unmonitored reaches (e.g. Soto, 2016; Segura et al. 2015).

In the light of the limited data available for the Globaqua basins, it is recommended that RWT is forecasted only as a function of air temperature Ta according to Moheseni et al. (1998) approach, disregarding the impact of discharge. Table 3 indicates the likely error that can be expected in the application across the basins. While RMSE are larger than what could be expected in fitting single station relationships, they are still low $(<3.5$ $\left.{ }^{\circ} \mathrm{C}\right)$. Yet, the low bias in the validation dataset $(<+/-5 \%)$ and the high coefficient of determination $(\mathrm{R} 2>0.75)$ give confidence that relative changes in scenario evaluations at the basin scale can be assessed with this simple approach. As in any regression, extrapolation to conditions outside the calibration observed ranges should be handled with care (Arismendi et al., 2014). Further, RWT in reaches that are highly impacted by upstream human activities (e.g. reservoirs, large withdrawals and releases of water) is unlikely to be properly simulated (Mohseni et al., 1998: Webb et al., 2008). 
Vigiak et al., Empirical modelling of river water temperature in water scarce Mediterranean basins

\section{ACKNOWLEDGMENTS}

This work has received funding from the European Union's Seventh Programme for research, technological development and demonstration under grant agreement No. 603629 - project "Globaqua". We are grateful to Globaqua partners that provided the basin datasets.

\section{REFERENCES}

Arismendi, I., Safeeq, M., Dunham, J.B., Johnson, S.L. (2014). Can air temperature be used to project influences of climate change on stream temperature? Environmental Research Letters, 9, 084015.

Cassie, D. (2006). The thermal regime of rivers: a review. Freshwater biology, 51, 1389-1406.

Letcher, B.H., Hocking, D.K., Whiteley, A.R., Nislow, K.H., O’Donnell, M.J. (2016). A hierarchical model of daily stream temperature using air-water temperature synchronization, autocorrelation, and time lags. PeerJ4:e1727.

Mohseni, O., Stefan, H.G., Erickson, T.R. (1998). A nonlinear regression model for weekly stream temperatures. Water Resources Research, 34, 2685-2692.

Mohseni, O., Erickson, T.R., Stefan, H.G. (2002). Upper bounds for stream temperatures in the contiguous United States. Journal of Environmental Engineering ASCE, 128, 4-11.

Morrill, J.C., Bales, R.C., Asce, M., Conklin, M.H. (2005). Estimating stream temperature from air temperature: implications for future water quality. Journal of Environmental Engineering, 131, 139-146

Punzet, M., Voß, F., Voß, A., Kynast, E. (2012). A global approach to assess the potential impact of climate change on stream water temperatures and related in-stream first-order decay rates. Journal of Hydrometeorology, 13, 1052-1065.

Pyka, C., Jacobs, C., Breuer, R., Elebrs, J., Nacken, H., Sewilam, H., Timmerman, J. (2016). Effects of water diversion and climate change on the Rur and Meuse in low-flow conditions. Environmental Earth Science, 75, 1206.

Segura, C., Caldwell, P., Sun, G., McNulty, S., Zhang, Y. (2015). A model to predict stream water temperature across the conterminous USA. Hydrological Processes, 29, 2178-2195.

Soetaert, K., Petzold, T. (2010). Inverse modeling, sensitivity, and Monte Carlo analysis in R using FME package. Journal of statistical software, 33, 1-28.

Sohrabi, M., Benjankar, R., Tonina, D., Wenger, S.J., Isaak, D.J. (2017). Estimation of daily stream water temperatures with a aBayesian regression approach. Hydrological Processes, 31, 1719-1733.

Soto, B. (2016). Assessment of trends in stream temperatures in the north of the Iberian Peninsula using a nonlinear regression model for the period 1950-2013. River Research and Applications, 32, 1355-1364.

van Vliet, M.T.H., Ludwig, F., Zwolsman, J.J.G., Weedon, G.P., Kabat, P. (2011). Global river water temperatures and sensitivity to atmospheric warming and changes in river flow. Water Resources Research, 47, W02544.

van Vliet, M.T.H., Franssen, W.H.P., Yearsley, J.R., Ludwig, F., Haddeland, I., Lettenmaier, D.P., Kabat, P. (2013). Global river discharge and water temperature under climate change. Global Environmental Change, 23, 450-464.

Webb, B.W., Hannah, D.M., Moore, D. R., Brown, L.E., Nobilis, F. (2008). Recent advances in stream and river temperature research. Hydrological Processes, 22, 902-918. 